\title{
LA EXPANSIÓN DEL ESTADO ARGENTINO SOBRE LOS TERRITORIOS PATAGÓNICOS A FINES DEL SIGLO XIX: INTEGRACIÓN Y RESISTENCIA DE LOS PUEBLOS INDÍGENAS FRENTE A LA ESTRATEGIA RELIGIOSA-EDUCATIVA
}

\author{
Oscar Daniel Duarte ${ }^{1}$
}

\section{RESUMEN}

Hacia fines del siglo XIX el Estado argentino inició el proceso de ocupación de la Patagonia. Esto implicó la necesidad de extender las instituciones del Estado para la dominación de los pobladores originarios. Este artículo, resultado de investigaciones previas sobre la política de expansión estatal argentina en la Patagonia, propone dos ejes de análisis: por un lado, mostrar las limitaciones del Estado argentino para llevar sus instituciones al territorio valiéndose para ello de la actividad de otros sujetos tales como la congregación salesiana. Por otro lado, mostrar las estrategias con las que el Estado nacional, los salesianos y los pobladores originarios se vincularon, especialmente por medio de la educación, integrando el territorio al mercado y al Estado argentino.

Palabras clave: educación, congregación salesiana, Patagonia, Argentina.

${ }^{1}$ Universidade de Buenos Aires (UBA), Buenos Aires, Argentina. 


\title{
A EXPANSÃO DO ESTADO ARGENTINO SOBRE OS TERRITÓRIOS PATAGONIANOS NO FIM DO SÉCULO XIX: INTEGRAÇÃO E RESISTÊNCIA DE POVOS INDÍGENAS CONTRA A ESTRATÉGIA RELIGIOSA- EDUCACIONAL
}

\section{RESUMO}

No final do século XIX, o Estado argentino iniciou o processo de ocupação da Patagônia. Isso implicava a necessidade de ampliar as instituições do Estado para dominar os povos nativos. Este artigo, resultado de pesquisas anteriores sobre a política de expansão do estado argentino na Patagônia, propõe dois eixos de análise: por um lado, mostrar as limitações do Estado argentino para levar suas instituições ao território, utilizando a atividade de outros atores, como a Congregação salesiana. Por outro lado, mostre as estratégias com as quais o Estado nacional, os salesianos e os colonos originais estavam ligados, especialmente através da educação, integrando o território ao mercado e ao Estado argentino.

Palavras-chave: educação, congregação salesiana, Patagônia; Argentina.

\section{THE EXPANSION OF THE ARGENTINE STATE ON THE PATAGONIAN TERRITORIES AT THE END OF THE XIX CENTURY: INTEGRATION AND RESISTANCE OF INDIGENOUS PEOPLES AGAINST THE RELIGIOUS- EDUCATIONAL STRATEGY}

\begin{abstract}
Towards the end of the 19th century, the Argentine State began the process of occupying Patagonia. This implied the need to extend the State institutions for the domination of the original settlers. This article, the result of previous research on the policy of Argentine state expansion in Patagonia, proposes two axes of analysis: on the one hand, to show the limitations of the Argentine State to take its institutions to the territory, using the activity of other subjects such as the Salesian Congregation. On the other hand, to highlight the strategies with which the national State, the Salesians and the original settlers were linked, especially through education, integrating the territory to the market and the Argentine State.
\end{abstract}

Keywords: education, salesian congregation, Patagonia, Argentina. 


\section{L'EXPANSION DE L'ÉTAT ARGENTINE SUR LES \\ TERRITOIRES PATAGONIENS À LA FIN DU XIX SIÈCLE: \\ INTÉGRATION ET RÉSISTANCE DES PEUPLES \\ AUTOCHTONES CONTRE LA STRATÉGIE RELIGIEUSE- ÉDUCATIVE}

\section{RÉSUMÉ}

Vers la fin du XIX siècle, l'État argentin a entamé le processus d'occupation de la Patagonie. Cela impliquait la nécessité d'étendre les institutions de l'Etat pour la domination des peuples autochtones. Cet article, fruit de recherches antérieures sur la politique d'expansion de l'État argentin en Patagonie, propose deux axes d'analyse: d'une part, montrer les limites de l'État argentin à prendre ses institutions sur le territoire, en utilisant l'activité d'autres sujets tels que la congrégation salésienne. D'autre part, montrez les stratégies avec lesquelles l'État national, les salésiens et les premiers colons étaient liés, en particulier par l'éducation, en intégrant le territoire au marché et à l'État argentin.

Mots-clés: education, congrégation salésienne, Patagonie, Argentine. 


\section{INTRODUCCIÓN}

El desarrollo capitalista en Argentina, hacia fines del siglo XIX, requirió de la expansión de la frontera agraria frente al impacto del crack económico de $1873^{2}$ y la caída en los precios de las materias primas a escala mundial. Esta crisis aceleró, en el caso argentino, la ocupación de los territorios patagónicos con el objetivo de incluir dichas zonas al control del Estado y, una vez concretada la tarea, vincular la región al mercado mundial.

A partir de esta perspectiva general nuestro trabajo propone un estudio dual. Por un lado, observar los esfuerzos realizados por el Estado en pos de la implementación de un aparato educativo nacional, así como la activa participación de la congregación salesiana desde una estrategia educativoreligiosa. Esta tarea, a su vez, se desenvolvió sobre una población originaria sobreviviente de las campañas de exterminio (centralmente las de 1878 a 1885), desperdigadas por todo el territorio, y sobre pequeñas colonias fundadas por inmigrantes europeos, particularmente en la costa del Chubut.

La extensión del territorio; las carencias económicas del Estado (en particular post-crisis); y la falta de desarrollo de un organismo magisterial (por ser un proceso aun en germen); muestran los límites de la expansión de la propuesta educativa estatal sobre el territorio. Frente a estas insuficiencias, el gobierno nacional se vio en la obligación de aceptar la participación de órdenes religiosas, autoimponiendo límites a su propuesta de expansión estatal laica.

Por otro lado, intentaremos ver las formas de integración que desarrollaron esos pobladores frente a un panorama novedoso de dominación. Para dicha tarea nos centraremos específicamente en el análisis de las Memorias del ministerio de justicia, culto e instrucción pública desde donde intentaremos exponer la visión que se tenía sobre los pobladores indígenas, sobre las tareas necesarias a realizar, y sobre la Orden religiosa que desenvolvió

\footnotetext{
${ }^{2}$ Un estudio que sirve de base para establecer la relación existente entre el impacto económico de la crisis de 1873 y el direccionamiento definitivo de la propuesta educativa nacional fue trabajado en profundidad en Duarte (2016).
} 
su actividad en el territorio.

Hacia fines del siglo XIX se presentó una constante en la región patagónica, la carencia de instituciones tales como juzgados de paz, sacerdotes ordenados en el país, y escuelas.3 Interpretamos así la existencia de límites en el desarrollo estatal en la región cuyas carencias forzaron a una fracción de la elite gobernante (en particular a los ministros del área) a aceptar propuestas alternativas -tanto en educación como con la presencia de sacerdotes ordenados en el extranjero-, tal como ocurrió en el caso de la "Familia Salesiana"4.

Esta Orden desempeñó una tarea que el Estado argentino no alcanzó a cumplir durante ese período, educar en los marcos del nuevo sistema de dominación. Bajo la apariencia de "civilizar a los indígenas", se orientó al desarrollo de las necesidades del mercado capitalista que se imponía en el territorio.

En nuestro análisis de este fenómeno pudimos profundizar en la visión que desarrollaron los salesianos sobre los pueblos originarios con los que establecieron contacto, y describir el vínculo que existió entre ellos y el Estado. A su vez hemos profundizado en las formas simbólicas con las que los pueblos originarios interpretaron y se adaptaron al nuevo orden. Para ello estudiamos algunos de los informes (siempre provenientes de fuentes estatales) que recuperaron la "voz de los indígenas" ilustrando lo que podemos interpretar como estrategias de resistencia e integración.

Para poder desarrollar esta tarea, el trabajo da inicio con la realización de una breve disertación en torno a la problemática de la dominación-

3 Estas instituciones, jurídicas, religiosas y educativas (tan importantes en el proceso de formación estatal) se encontraban centralizadas por el Estado argentino hacía fines del siglo XIX y principios del siglo XX, bajo la órbita del Ministerio de Justicia, Culto e Instrucción Pública.

4 Se conoce como Familia Salesiana al conjunto de instituciones fundadas por la congregación salesiana, siguiendo las enseñanzas de Juan Bosco. Las que contaban con reconocimiento de la Santa Sede hacia fines del siglo XIX eran las Hijas de María Auxiliadora, los Salesianos de Don Bosco, y la Asociación de Salesianos Cooperadores. 
integración, como imposición desde el poder pretendidamente hegemónico del Estado, frente a tácticas de supervivencia de los pueblos dominados.

\section{LAS TAREAS DEL ESTADO}

Hacia fines del siglo XIX, diferentes sectores de la dirigencia política argentina (de su elite ilustrada e incluso de los miembros más prominentes del sector productivo), habían comprendido la importancia de contar con un aparato escolar que impusiera los lineamientos educativos necesarios sobre toda la población del territorio. Se proyectaron diversos lineamientos para la educación durante las décadas de 1860, 1870 y 1880. Pero los debates concluyentes se desarrollaron durante la realización del Congreso Pedagógico5 que tuvo su corolario con la sanción de la Ley $1420,{ }^{6}$ de educación obligatoria, gratuita y gradual a implementarse en los Territorios Nacionales. 7

Sin profundizar en los debates entablados en torno al tema, estos se referían centralmente a la construcción definitiva de un sistema escolar que actuará como aglutinador de diversas experiencias sociales para, a través de un armado que intentaba ser homogeneizador, dar paso a la estructuración definitiva de una Nación.

La existencia de una burguesía intermediaria, ligada al latifundio y poseedora del control político del Estado, contrastaba con una masa

\footnotetext{
5 Fue un congreso internacional organizado por el Estado argentino en 1882. En el mismo se discutieron los principales lineamientos de la propuesta educativa para el Estado nacional que luego se plasmarían en la ley 1420 de educación común. Del mismo participaron los principales referentes del ámbito nacional e internacional con delegaciones como la uruguaya, boliviana y brasilera. Para profundizar en este tema se puede consultar a Recalde (1987).

${ }^{6}$ La Ley 1420, en principio, solo determinó lineamientos normativos para la Capital Federal y los Territorios Nacionales. No obstante, las provincias fueron paulatinamente adaptando su propuesta a las directivas de esta ley.

7 Los Territorios Nacionales, a diferencia de las Provincias, no contaban con autonomía política y eran dirigidas administrativamente desde el Poder Ejecutivo Nacional. La Patagonia era considerada todo un Territorio Nacional dividido en regiones que posteriormente, con el crecimiento de las poblaciones y el afianzamiento del Estado, se fueron convirtiendo en Provincias.
} 
mayoritaria, explotada y dominada, tanto en las ciudades como en las campañas. Esa población mayoritaria debía ser instruida en los lineamientos político-económicos ${ }^{8}$ requeridos por el Estado, para lo cual se dio impulso al desarrollo de instituciones educativas, pero también desde las áreas de la justicia y el culto. Todas estas responsabilidades recaían, para la época, sobre el ministerio de justicia, culto e instrucción pública que controlaba y dictaba las normativas para cada una de estas áreas.

Fue así que, desde este ministerio, se intentó identificar con claridad cuáles eran las tareas que el Estado debía afrontar. Ellas se vincularon centralmente al control e instrucción de la población explotada. El sector social que definió dichas tareas se conformaba por personajes de una elite ilustrada, muchas veces afín al grupo dominante por medio de redes familiares o por contactos en torno a afinidades políticas.

Como resultado de estos debates los miembros de esta elite lograron identificar los diferentes subgrupos que conformaban a los sectores bajos de la sociedad sobre los cuales debía impactar la propuesta educativa. Los inmigrantes, los criollos pobres (aquellos que no habían accedido por su clase social a vincularse con los sectores patricios) y, por supuesto, las poblaciones indígenas. 9 Pero a su vez, estos últimos, en sus diferentes estrategias frente a la imposición de la "civilización" - sean por parte de la iglesia como por parte del Estado - disputaban por sostener particularidades identitarias o, incluso, de integración, marcando sus diferencias respecto a otros grupos que se encontraban en igual situación de opresión.

\footnotetext{
8 En el caso argentino, los lineamientos políticos que más preocupaban a la elite dirigente se referían a la conformación de un cuerpo nacional en el contexto de una profundización de la política inmigratoria y de incorporación de pobladores originarios. Respecto a lo económico, los lineamientos venían de la mano de la formación de una mano de obra, de baja cualificación, ligada a la producción agrícola-ganadera o vinculada a pequeños sectores artesanales urbanos.

9 En la prolífica obra de Domingo Faustino Sarmiento se pueden encontrar referencias a estos grupos que debían ser educados o eliminados, vease Condición del extranjero en América o Facundo, civilización y barbarie.
} 


\section{EL “OTRO” EN LA PATAGONIA ARGENTINA DE FINES DEL SIGLO XIX}

Entendemos que toda fragmentación al interior de los sectores oprimidos responde, a grandes rasgos, a una de las siguientes variables; o responde a una estrategia de dominación, o bien a una estrategia de integración. La segmentación se encuentra subordinada a necesidades de identificación, pero también fortalece la sectorización de las demandas, el enfrentamiento entre grupos subordinados y la fragmentación de las luchas frente a un poder pretendidamente hegemónico.

La característica más consecuente de la construcción de un "otro" responde a la constancia de su desposesión; tal como afirma Rita Segato tanto la esclavitud y el servilismo al que estuvieron obligados los pueblos originarios, fueron "[...] en su origen, instituciones de carácter bélico, resultado de la conquista territorial de jurisdicciones tribales y cuerpos pertenecientes a esas jurisdicciones - y económica - como una forma particular de extracción de riqueza del trabajo." (2007, p. 23).

A la desposesión le sigue generalmente la imposición de nuevas normativas dictadas por el sector que se impone. En la Patagonia Argentina de la Generación del Ochenta10 resaltaron dos grupos de "otros" dentro del universo conformado por la clase explotada; por un lado los inmigrantes, por otro las poblaciones indígenas.

Si la versión dominante del "crisol de razas" a la argentina predica que "los peruanos vinieron de los incas; los mejicanos de los aztecas; y los argentinos, de los barcos", las implicancias de semejante aseveración inscriben al menos un doble juego. A la par de trazar distancias nítidas respecto de ciertos otros extremos (los "aindiados hermanos" de ciertos países latinoamericanos) en base a un ideario de nación homogéneamente blanca y europea, se secuestra y silencia

${ }^{10}$ Se llamó "Generación del Ochenta" a los miembros de la elite cultural y política que lograron afianzarse en el poder del Estado argentino a partir de 1880 durante la presidencia de Julio A. Roca. 
internamente la existencia de otro tipo de alteridades, como la de los pueblos indígenas -supuestamente, siempre pocos en número y siempre a punto de terminar de desaparecer por completo-[...] (BRIONES, 2008, p. 20-21).

Fue producto de la crisis económica de 1873 que se impulsó, desde la dirección política del Estado, la ocupación definitiva de los territorios patagónicos. El objetivo contaba con múltiples aristas entre las que podemos subrayar; por un lado, el prestigio político (con la incorporación y el reparto de las tierras); por otro, la salida a dicha crisis incorporando tierras al circuito de la agro ganadería vinculando definitivamente al país al mercado mundial. "A la expansión del país en el marco del capitalismo dependiente, le correspondió el crecimiento del poder estatal como necesaria instancia articuladora de la sociedad civil.” (BANDIERI, 2000, p. 127). Sin embargo, las carencias del Estado (sobre todo en lo económico) limitaron su alcance, permitieron el surgimiento de otras experiencias de formación y, por lo tanto, otras caracterizaciones respecto a la población originaria del lugar.

Es factible decir que en la Patagonia de fines del siglo XIX, casi la totalidad de su población estaba conformada por esos "otros" - remitiéndonos a la caracterización hecha por la oligarquía terrateniente y la elite gobernante -. El territorio contaba con colonias fundadas por pobladores europeos (como fueron los casos de los galeses en la región del Chubut); una cantidad importante de trabajadores migrantes de origen europeo (particularmente italianos) más otros de países limítrofes (chilenos); misiones de la orden salesiana (ordenación que vio sus orígenes en Turín); y, finalmente, los pueblos originarios (mapuches, ranqueles y tehuelches). ${ }^{11}$

Es posible afirmar que, desde la visión de la elite cultural vinculada al gobierno nacional - y por lo tanto desde la directriz impuesta por el Estado -, la división más tajante entre esos "otros” remite a la barrera cultural dada por la

\footnotetext{
${ }^{11}$ La población indígena sobre la que hacen referencia mayormente las fuentes seleccionadas, y
} por lo tanto sobre la que se basa este trabajo, es la Tehuelche. 
composición de sociedades ya vinculadas al modo de producción capitalista con aquellas que aún no se encontraban subordinadas a este. La "supremacía cultural blanca" (la de los colonos o incluso los inmigrantes que se vinculaban de una u otra forma al mercado nacional en los términos planteados por las necesidades del desarrollo capitalista) frente a la de los "aborígenes" (con una lógica de producción y subsistencia independiente) determinó que la "civilización" se diera de bruces con la construcción posterior del "crisol de razas".

Segato (1998b) destaca que distintos países pueden echar mano a un mismo tropo, aunque para realizar operaciones cognitivas diversas. Señala entonces que, aun partiendo de la metáfora del "crisol de razas", las ideologías nacionales hegemónicas de Estados Unidos, Brasil y Argentina han administrado de manera dispar la tensión entre la homogenización de ciertas poblaciones como núcleo duro de la nacionalidad, la heterogeneización de otras como distintos tipos de otros internos diferencialmente posicionados respecto de las estructuras de acceso a recursos materiales y simbólicos clave. Así, explicita Segato que, en Argentina, la metáfora del crisol usada para construir una imagen homogénea de nación ha ido inscribiendo prácticas de discriminación generalizada respecto de cualquier peculiaridad idiosincrática y liberando en el proceso a la identificación nacional de un contenido étnico particular como centro articulador de identidad (una nación uniformemente blanca y civilizada en base a su europeitud genérica) (BRIONES, 2008, p. 21).

Frente a las limitaciones que encontró el Estado (producto de carencias de financiamiento, de formación de maestros disponibles y materiales) de alcanzar esos territorios, fue la Congregación Salesiana la que afrontó (desde una perspectiva evangelizadora) la tarea de impartir educación en la región. El gobierno nacional debió aceptar ser sustituido a fin de contar (al menos mientras no pudiera tener una presencia fuerte) con un ordenador moral para los habitantes del lugar.

La política agresiva del Estado, luego de sucesivas campañas militares, viró parcialmente. La creencia respecto a la imposibilidad de absorber a los 
indígenas bajo la "civilización" capitalista (con el agregado de encontrarse asentados en tierras necesarias para el avance de este modo de producción en Argentina) alentó una política de exterminio y ocupación de tierras. Posteriormente los pobladores originarios que no fueron eliminados serían catalogados de "infieles" o - entre aquellos que lograban ser dominados - de "indios amigos" o "hermanos menores" sumiéndolos en una evidente categoría de subordinación.

\section{LA EDUCACIÓN EN LA PATAGONIA A FINES DEL SIGLO XIX}

El proceso de conformación estatal argentino, tal como se dio en otras regiones, buscó la estructuración de un espacio nacional organizado en relación a su participación en el mercado capitalista. Este proceso no fue pacifico, ni libre de contradicciones, y abrió al interior del país toda una serie de conflictos bélicos y políticos en pos de la imposición de una línea programática para el devenir estatal.

El debate político de la época incluía también el debate pedagógico que puede sintetizarse en el caso argentino (según señala Adriana Puiggrós) entre dos perspectivas.

Esas dos orientaciones, una enciclopédica y la otra práctica, serían materia de discusión en las décadas siguientes tanto entre un sector más tradicionalista y otro más moderno de la oligarquía, como entre ésta última y los sectores medios. Cada una de las posiciones en juego provenía de un imaginario distinto: algunos soñaban con un país de estancias donde una fuerte autoridad pusiera orden entre inmigrantes, anarquistas y demás peligros sociales, y otros imaginaban posible un país de gente industriosa que abriera fuentes de trabajo y modernizara sus instituciones (PUIGGRÓS, 2009, p. 79).

Una vez superadas las contiendas entre los diferentes sectores que 
disputaron el control del Estado, la nueva fracción gobernante accedió al poder con un programa definitivo: eliminar toda oposición interna, organizar el Estado - con una propuesta educativa unificada- y vincular dicho Estado al mercado mundial. La tarea de incorporar tierras (para superar la crisis potenciando el desarrollo agro ganadero) fue impulsada por ese mismo grupo político que afrontó la tarea de conquistar definitivamente los territorios Patagónicos. Sin embargo, una vez ocupados, el Estado se vio en la necesidad de hacer llegar hasta allí sus instituciones de todo orden.

Entre 1881 y 1884, el gobierno del presidente Julio A. Roca incorporó bajo la administración nacional los territorios patagónicos que actualmente incluyen a las provincias de Rio Negro, Chubut, Santa Cruz y Tierra del Fuego. Mediante la Ley 1532/1884 de "Organización de los territorios nacionales" buscó demarcar el espacio geográfico, ordenar la forma de gobierno, e impulsar los subsidios para el desarrollo de la educación pública. Sin embargo, una multiplicidad de problemas retrasó la tarea respecto a la organización del sistema educativo en los territorios patagónicos, lo que se vio reflejado en los informes de los inspectores que, enviados por el Estado, debían rendir cuentas sobre la situación real.

Algunos pobladores locales, y luego los sectores ilustrados de la elite, exigían la presencia del Estado en los territorios -mediante resoluciones y subvenciones- tal como lo explicita la primer editorial de la revista El monitor de la educación común (1881) ${ }^{12}$ cuando plantea que la revista era producto de la necesidad por conocer el estado de la educación en los Territorios y por dar a conocer las resoluciones tomadas por el Consejo Nacional de Educació. (SARMIENTO, 1881).

Como es de suponer, el primer problema que debió enfrentar la

12 El Monitor de la Educación Común fue la revista publicada por el Consejo Nacional de Educación desde 1881 hasta (con interrupciones) el presente. Se comportaba como una herramienta de información desde la que se bajaba a directivos, inspectores y maestros la situación de la educación en el país y las normativas a seguir, así como diversos debates y otras herramientas didáctico-pedagógicas. 
propuesta estatal en los Territorios del sur estuvo referido a la ausencia de establecimientos. En las Memorias del ministerio o incluso en la revista $E l$ Monitor aparecen reflejados varios reclamos por parte de los pobladores del lugar y, posteriormente, de los inspectores, por la apertura de edificios que sirvan a esta tarea. Pero la tarea se desarrollaba muy lentamente, producto de la ineficiencia y las carencias económicas.

\begin{abstract}
Los intereses objetivos de estos sectores se transforman en valores socialmente aceptados en la medida en que se observa con marcado desaliento la ineficiencia o lentitud de la acción del estado nacional en relación a los diversos problemas que afectan la calidad, expansión y continuidad de la educación pública en sus primeros treinta años (RUIZ, 2006, p. 17).
\end{abstract}

Tanto los comisarios, como los inspectores, escribieron cartas al Consejo Nacional de Educación y al ministerio de instrucción informando sobre las necesidades escolares y la reticencia de la población - tanto los colonos como los indígenas - hacia la educación nacional. La falta de escuelas públicas en la mayoría del territorio; la carencia de recursos allí donde existían; la ausencia de inspectores locales o de maestros aptos para la tarea; y la fuerte presencia de experiencias alternativas al Estado prevalecen en sus informes.

Haciendo referencia al trabajo de Adriana Puiggrós retomamos el concepto de "Alternativas Pedagógicas" desde la perspectiva que las mismas muestran las insuficiencias de la propuesta pretendidamente hegemónica. Nos concierne, al igual que a la autora, especificar que "[...] el tratamiento de las alternativas no nos interesa como 'estudios de casos', sino de síntomas que denuncian procesos. La denuncia se realiza por la negación, la descalificación, la sobrevaloración $\mathrm{u}$ otros tratamientos discursivos de muchas de esas alternativas" (PUIGGRÓS, 2006, p. 23). Por lo tanto, vemos en las experiencias alternativas ejemplos para describir la carencia que el Estado argentino tenía en materia de educación todavía a fines del siglo XIX. 
Debemos afirmar entonces que este territorio no carecía de otras experiencias escolares. En aquellos territorios donde el Estado no llegaba a implementar su política, surgieron variantes que respondieron a las necesidades educativas de la población local. Por un lado las escuelas fundadas por colonos europeos (principalmente en las colonias galeses); pero también las escuelas confesionales, en particular de la Orden Salesiana. La educación, como necesidad humana, ocupaba estos espacios aun antes de la llegada del Estado nacional.

En los informes de los inspectores enviados por el ministerio se registró, además, una multiplicidad de problemas como: la ausencia de inspectores locales; lo magro de los sueldos, bajos y para nada atractivos, por lo que el Consejo Escolar debía costear los gastos; que los preceptores debían poder jubilarse luego de 15 años de servicios; que los métodos de enseñanza eran nulos; y que los maestros eran caracterizados como ignorantes que, en muchos casos, no sabían leer ni escribir. Un problema adicional estaba referido al hecho que el calendario escolar - que se referenciaba en el calendario académico utilizado de la Capital Federal - era considerado "no apto" para la educación en el sur argentino.

Fueron los inspectores enviados desde Buenos Aires quienes realizaron el relevamiento de los problemas, escucharon los reclamos y enviaron propuestas al ministro con el fin de resolver los problemas. Un ejemplo de ello es el informe enviado por el inspector Raúl Díaz, ${ }^{13}$ quien propone (debido a las temperaturas extremadamente frías del territorio en invierno) cambiar la fecha del ciclo lectivo para el Chubut, Santa Cruz y Tierra del Fuego iniciando las clases el primer lunes de agosto para finalizar el 31 de mayo, en el horario que iba de las 12 a las 16 horas.

La Patagonia, carente de escuelas suficientes, con grandes distancias

\footnotetext{
${ }^{13}$ Raúl B. Díaz fue el primer inspector de escuelas en los Territorios Nacionales a partir de 1890. En sus informes sobre la situación de la educación en la Patagonia se pueden constatar varias críticas al desarrollo de la educación en estos territorios, así como reclamos y pedidos para el progreso de la tarea. Para profundizar en el tema se puede consultar Fiorucci (2015).
} 
difíciles de cubrir por la escasez de caminos y la ausencia de fondos para el desarrollo, provocaba dificultades a la hora de encontrar la solución para afrontar la tarea de educar las diferentes comunidades apostadas en los territorios del sur.

Benjamín Zorrilla, presidente del Consejo Nacional de Educación entre 1882 y 1895, describió perfectamente la situación. El carácter heterogéneo y apartado de esas poblaciones hacía indispensable la presencia de la escuela nacional para impartir allí conocimientos "nacionales".

\begin{abstract}
La enseñanza de la lengua nacional, Historia Argentina y principio de instrucción cívica, ha sido especialmente encomendada a los preceptores de esas escuelas [...] La escuela en las colonias y territorios debe ser el mejor medio y más eficaz para atraer a sus pobladores a nuestras costumbres, a nuestros hábitos y hasta hacerles comprender el respeto y obediencia que deben a nuestras leyes y autoridades (ZORRILLA, 1886, p. X).
\end{abstract}

Fue Nicanor Larraín, ${ }^{14}$ en su calidad de informante, quien recomendó la educación en el "idioma del país" para las escuelas de las colonias. Según el relato, en su territorio existían siete iglesias protestantes, de "las sectas metodistas, anabaptistas e independientes". Al igual que con las escuelas y el idioma, no se encontraban "iglesias del país". Esta referencia constante a los elementos "del país"; iglesia, idioma, escuelas; muestra la preocupación de estos personajes al notar que el Estado -o el país en sus palabras-, aún no alcanzaba a ocupar con toda su fuerza los territorios de frontera.

Desde el Estado se manifestó la necesidad de colonización cultural de todo un amplio espectro territorial ocupado por pobladores de diverso origen. Las propuestas impulsadas por los miembros de la elite ilustrada buscaron poner bajo control "ideológico" a toda la población. Sin embargo, fueron las carencias económicas y materiales las que limitaron ese desarrollo sumiéndola a

\footnotetext{
14 Nicanor Larraín fue un pensador sanjuanino quien actuó como cronista y narrador sobre la
} vida en la Patagonia luego de un autoexilio iniciado en la década de 1880. 
las dificultades antes descritas. A pesar de haber impulsado en toda la primera mitad de la década de 1880 una política expansiva, el Estado carecía de los medios para llegar a cubrir con su propuesta estos espacios.

Frente a este problema la idea de centralización impulsada desde el Estado encontró sus propios límites. La falta de fondos, así como de un personal preparado y dispuesto, obligó a las autoridades a aceptar una convivencia con escuelas alternativas a su propuesta, en la medida que se consolidaba su propia experiencia. Las escuelas fundadas por los colonos para brindar educación a sus propios habitantes fueron un puntal del desarrollo patagónico, sin embargo fueron las órdenes salesianas las que se propusieron afrontar la tarea de "incluir" a la población indígena, educarlas mediante el trabajo y caracterizarlas presentando informes al Estado nacional.

\section{LOS SALESIANOS EN LA PATAGONIA}

En su estudio sobre las escuelas salesianas en la Patagonia, María de los Milagros Pierini (2010) describe la ausencia del Estado Nacional en Santa Cruz y, como producto de ese hecho, el desarrollo de una lógica educativa contradictoria entre un Estado laico que, producto de sus falencias, veía crecer dentro de su territorio opciones educativas confesionales.

Como ocurrió en el resto de Argentina, en la Patagonia la tarea educativa desarrollada por los Salesianos fue la más importante, la que alcanzó a todos los grupos sociales y no sólo los sectores populares como era el objetivo inicial de Don Bosco y la que le permitió trascender los límites de lo religioso para llegar a ámbitos más amplios. Si bien lo hicieron en una etapa de secularización e implementación del laicismo desde las autoridades del Consejo Nacional de Educación, lo que le trajo no pocos conflictos con el Estado, quizás los más importantes escollos que tuvieron que superar fue lo extenso y desconocido de las regiones en las cuales ingresaron con un clima y una geografía que sobrepasaban al hombre y las características de su población entre las que podemos mencionar su escasez, su dispersión, el predominio de los extranjeros lo que, en el 
caso de los chilenos se veía agravado porque era una población migrante por motivos laborales, la existencia de grupos religiosos protestantes, que era más importante en el caso del Territorio del Chubut por la existencia de las colonias galesas, la presencia de ideologías anticlericales, aunque en lo referido a los socialistas y anarquistas tenían menos importancia que lo que el Estado nacional y los Salesianos denunciaban y, lo más importante para el tema educativo, lo reducido de la población infantil lo que provocó frecuentes rencillas entre la escuela salesiana y la oficial que se acusaban mutuamente de "robarse" alumnos (PIERINI, 2010, p. 225).

Es así que la congregación de los salesianos fue ocupándose de aquellas tareas que el Estado todavía dejaba de lado; la educación, el cuidado de huérfanos y de los menores procesados. En una de sus hipótesis María Andrea Nicoletti plantea que, "El proyecto pedagógico salesiano ofrecía una educación integral y moral cristiana, que favoreció el propósito de "argentinización" de un territorio recientemente conquistado" (2002/2003, p. 137). El nuevo orden católico separaba, entre los indios, a los civilizados de los salvajes, buscando en la causa de evangelización el proceso de "homogenización cultural”.

En muchos lugares de la Patagonia, incluyendo Santa Cruz, la escuela salesiana -aun siendo calificada de "dogmática y retrograda" por los defensores del laicismo- fue la única opción educativa frente a una escuela oficial que a veces no existía o -si lo hacía- era con múltiples falencias que los mismos informes oficiales se encargaban de denunciar (PIERINI, 2010, p. 251).

No obstante, la irrupción de la escuela salesiana implico una visión particular de estos sobre los pueblos nativos del territorio.

\section{SALESIANOS, INDÍGENAS Y ESTADO EN LA PATAGONIA DE FINES DEL SIGLO XIX.}

A pesar de la ausencia del Estado en el territorio patagónico 
(confirmado en la falta de personal, instituciones sólidas y presupuestos adecuados) el ministerio de justicia, culto e instrucción pública se encargó de recolectar los informes recibidos desde allí, de impulsar directivas e iniciativas y de presentar dichos informes año tras año al Congreso Nacional. Como encargado de la educación y el culto nacional, el ministerio se ocupó centralmente del seguimiento de estas tareas tan ligadas a la idea de civilización. En dichos informes se pueden ver las caracterizaciones hechas por los misioneros sobre los indígenas de la región.

En uno de sus trabajos sobre la tarea de los salesianos en Tierra del Fuego, María Andrea Nicoletti (2008) describe dos modelos de evangelización desarrollados por los salesianos en el sur argentino. La "Familia Salesiana" desplegó allí un circuito de misiones y colegios ${ }^{15}$ - contaban para la época con ocho residencias misionales y cinco de las Hermanas de María Auxiliadora - de acuerdo a dos modelos de evangelización. Entonces, según la autora, existían misiones volantes, diseñadas por el Vicario Giovanni Cagliero encargadas de circular (o visitar) por los poblados dispersos; y las reducciones, circunscriptas a la isla de Tierra del Fuego, ideadas por el Prefecto Giuseppe Fagnano y reducidas a ciertos espacios. ${ }^{16}$

La problemática indígena fue, en un principio, soslayada en tanto que la política de exterminio y la caracterización de "incivilizados" -como pueblos incapaces de ser civilizados- no planteaban una integración, ni siquiera, en los términos políticos de ese Estado emergente. La preocupación más inmediata respecto a la educación, ya entrando en la década de 1880, se vinculó a la problemática del migrante europeo.

\footnotetext{
${ }^{15}$ Según los informes estudiados para este trabajo, se impartía instrucción a unos 1500 alumnos en dieciséis colegios distintos. Entre ellos se encontraban las Escuelas de Artes y Oficios y la Escuela de Agricultura de Viedma. Además de estos la congregación buscaba abrir un asilo de menores e indios en el poblado de Roca (Actual provincia de Rio Negro).

${ }_{16}$ En nota al pie del artículo de Nicoletti la autora explica que... "El Vicariato abarcaba los territorios de Neuquén, Río Negro y Chubut y la Prefectura Santa Cruz, Tierra del Fuego (incluyendo el lado chileno) e islas Malvinas" (NICOLETTI, 2008, p. 137).
} 
Es evidente la conveniencia de que la enseñanza revista carácter nacional; nuestro país posee ya dentro de sí un gran número de extranjeros que tratan de perpetuar sus tradiciones y hasta su credo político entre sus hijos, con peligro para nuestras instituciones y para el elemento nativo que perdería poco a poco su espíritu de nacionalidad y viviría en un medio cosmopolita, olvidando lo que corresponde al suelo y a la agrupación política.

La Nación tiene el derecho y el deber de conservarse por el amor de sus hijos y de preservar sus instituciones de las degeneraciones o modificaciones que las corrientes inmigratorias podrían imponerle. Es en nombre de ese derecho y de ese deber que la Comisión ha creído indispensable introducir en la Historia y la Geografía Argentina y la Instrucción Cívica, por que la Escuela es la refundación pacífica de las diversas creencias y tradiciones políticas en un solo crisol (MOLINA, 1886, p. 465).

Los encargados de dirigir la política educativa discutían sobre la inclusión de lineamientos que sirvieran para fortalecer la nacionalidad. "La escuela es concebida como un ámbito estratégico para la clasificación de la población y también para intervenir en el proceso de construcción de 'un ser nacional' [...]" (THISTED, 2014, p. 135). La "escuela nacional" buscaba rescatar los elementos nativos -entre los cuales de ningún modo se contempló a los indígenas- en pos de un ideario civilizatorio.

La cuestión migratoria cumplía el doble rol de darle un carácter civilizatorio al poblamiento del territorio al mismo tiempo que trataban de "perpetuar sus tradiciones y hasta su credo político" tal como se afirma Molina en la Memoria citada previamente. Para ellos estaba destinada la educación. Era el verdadero problema de la elite y la oligarquía gobernante. Mientras que entre 1881 y 1914 arribaron al país unos 4.200.00o inmigrantes, ${ }^{17}$ la población originaria, en el mismo período, descendió abruptamente.

La ausencia de escuelas del Estado en la Patagonia -o incluso de sacerdotes del país-, además del carácter disperso de las poblaciones originarias, colocó la tarea de la educación "cristiana y civilizada" en manos de los misioneros salesianos. Esas carencias obligaban al ministro a aceptar, como

17 Datos obtenidos del libro de Devoto (2003). 
una estrategia, la participación de órdenes eclesiásticas provenientes de países extranjeros.

Siendo estos los Seminarios más frecuentados y atendiendo a los datos ya referidos, podemos, sin riesgo de equivocarnos, enunciar, como conclusión general, que es verdaderamente lenta la formación del clero nacional y que por mucho tiempo necesitarán nuestros Prelados del elemento extranjero para responder a las exigencias de las parroquias y demás cargos eclesiásticos, si no los auxilia el Gobierno a fin de que puedan dar impulso a aquellos Establecimientos (BALESTRA, 1892, p. LXXXI).

\section{A continuación se afirma que;}

Luego, pues, el fomento de nuestros Seminarios está indicado como conviene al interés público y a la regularidad en las provisiones eclesiásticas, y yo opino que, aunque no fueran tan buenos como lo deseáramos los sacerdotes que en ellos se forman, siempre reemplazarían ventajosamente a los que pululan nuestras campañas, sacerdotes venidos de otras naciones que, si bien profesan el culto a Dios, no conocen ni profesan el culto y el amor a la patria argentina, del que no pueden prescindir nuestros seminaristas (BALESTRA, 1892, p. CXXXI-CXXXII).

La actividad de los padres salesianos fue entonces la que suplantó, no solo al clero local, sino incluso a la escuela nacional. La catequización llevaba al "desierto"18 elementos necesarios para la formación, en valores "civilizatorios", de esa población.

La catequización de indígenas se lleva a cabo, con éxito plausible, por diversas congregaciones en todos nuestros territorios desiertos. La figura simpática del misionero, en aquella lucha incesante y abnegada contra los peligros y las inclemencias del clima, se destaca é inspiran la mayor adhesión (BALESTRA, 1892, p. CXXXIII).

18 El concepto "Desierto" para referirse a la Patagonia fue el eufemismo utilizado por las autoridades de la época para hablar de aquellos territorios donde aún no había hecho pie la "civilización blanca". 
Las carencias por las cuales el Estado no podía desarrollarse en la Patagonia abrieron el juego a la participación de los salesianos. Nicoletti (2002/2003) afirma que la educación salesiana encontró un anclaje en la Patagonia, no solo por la demanda insatisfecha de educación estatal, sino por su iniciativa en la educación de sectores marginales como indígenas y migrantes. Allí, las misiones, desarrollaron toda una labor formativa dentro de los marcos "occidentales".

La educación propuesta adquiría formas absolutamente instrumentales: se formaba en el trabajo; se imponía una disciplina horaria que educaba dentro de los márgenes "civilizados" (que ya adelantaba maneras particulares de la forma de organización capitalista del trabajo); las misiones se autoabastecían (y hasta producían un mínimo excedente comercializable); este tipo de instrucción rompió con la lógica previa de los pobladores indígenas, regulada por otros tiempos y vinculada a la subsistencia y el intercambio simple. Es por ello que en el informe del Padre Arreche (uno de los misioneros del sur) sobre la situación de las misiones salesianas en Viedma se comunica;

Por el momento siguen funcionando los talleres de Sastrería, Zapatería, Carpintería, Herrería y Hojalatería, notándose en los aprendices de cada taller un singular empeño en dedicarse a su ramo, como también un progreso tan rápido en varios que causa admiración a sus mismos maestros, siendo la mayor parte de ellos indígenas (ARRECHE, 1893, p. 419).

En este informe del Padre Arreche, que luego fuera entregado a los funcionarios del Estado nacional, los eclesiásticos consideraban fundamental su labor para incorporar a los indígenas y convertirlos en miembros útiles de la sociedad. Es por eso que a continuación se plantea;

Estos artesanos tienen diariamente sus horas de instrucción literaria, de manera que nada les falte para poder un día ser útiles a sí mismos y a la Sociedad. Con ocasión de la exposición Colombiana de Génova se enviaron a Europa indígenas de la Patagonia y de la Tierra del Fuego, 
que habían sido educados desde muy niños en nuestros Colegios, alcanzando en todos los ramos un grado de instrucción y cultura que ha dejado admirados a cuantos se ocuparon de examinarlos. De tal manera la culta Europa pudo conocer que en extensos territorios de la Argentina, la Religión, representada por sus ministros y apoyada por las Autoridades nacionales, trabaja eficazmente para salvar y rehabilitar los últimos restos de esta población indígena, que fue siempre tan desgraciada (ARRECHE, 1893, p. 419-420).

Los misioneros explicaban lo fundamental de su tarea en beneficio de “esta población tan desgraciada”. La manifestación de los buenos resultados de su instrucción había, incluso, admirado a "la culta Europa" colocándola como parámetro de los logros obtenidos con los pobladores indígenas. La implantación de una nueva cultura era entendida así como un acto de caritativa salvación de unos hacia los "otros".

En el informe que el obispo titular de Magida, Juan Cagliero, ${ }^{19}$ escribe al ministro José Zapata ${ }^{20}$ en 1894, se describe el vínculo existente -de mutua necesidad- entre Estado y misiones. En ella el obispo intenta mostrar la importancia que cumplen las misiones al instruir a los infantes locales. Por otra parte, luego de manifestar la importancia de la tarea, se solicitan fondos (en formas de subvenciones) para asistir la obra.

El supremo gobierno siempre nos prestó su decidido apoyo moral y material para promover el adelanto de nuestras obras tan humanitarias no solo en favor de la conversión y civilización de los indígenas, sino también para la mejor instrucción y educación de la niñez desvalida.

Siendo misión especial de la Congregación Salesiana, a la cual tengo la honra de pertenecer, la educación de la niñez desvalida, hemos puesto todo nuestro empeño en abrir allá Colegios, Asilos, Recreatorios Festivos, Escuelas Industriales para niños, Escuelas Profesionales para niñas y Escuelas de Agricultura (CAGLIERO, 1894, p. 561-562).

\footnotetext{
19 Vicario apostólico de la Patagonia septentrional desde 1883. Nacido en Turín (Italia) en 1838, formó parte de la primera generación de sacerdotes formados por Juan Bosco.

${ }^{20}$ Ministro de Justicia e Instrucción Pública desde el 14 de abril de 1894 al 23 de enero de 1895, durante parte de la presidencia de Luis Sáenz Peña.
} 
Una vez esgrimido el principio "humanitario" de la tarea, el reconocimiento al apoyo del gobierno y de numerar las obras que allí se realizaban se expide, a continuación, la petición de fondos.

\begin{abstract}
Esta breve exposición de obras de caridad, de beneficencia y de enseñanza científica e industrial en favor de los Indígenas y de la niñez abandonada en las Misiones de la Patagonia, llamará, como es de esperar, la atención de su alta inteligencia, bondad y justicia, para que con los años anteriores, quiera ayudarnos con alguna subvención, para que siquiera en parte sufrague los grandes gastos que la Congregación Salesiana costea para la evangelización de aquellos vastos territorios de grande porvenir para la República Argentina (CAGLIERO, 1894, p. 563-564).
\end{abstract}

La obra de los salesianos no concluía solo en la educación a los indígenas. Como tarea evangelizadora cumplía con los sacramentos del bautismo, la confirmación y el matrimonio. El prefecto Fray Guido Depedri informó al ministerio en 1895 - ahora bajo la administración de Antonio Bermejo - que se habían realizado en su jurisdicción unos 650 bautismos. Pero en el mismo diferenció a las personas afirmando que 500 de ellos eran "cristianos" y 150 "indios". Las confirmaciones - otro sacramento que exige la iglesia católica - fueron para 400 cristianos y para cien indios. Es de destacar que la población indígena no era contabilizada entre los cristianos ni siquiera luego de bautizados o confirmados. El concepto de población cristiana era análogo al de población blanca.

Con el matrimonio se presentaba otro tipo de problema. Hacía la década de 1890, el Estado argentino pretendía llevar un control de la población a través de la implementación del Registro Civil. Una de las directivas impuestas a partir de entonces consistía en que se requería, antes de realizarse un matrimonio confesional, que el mismo debía estar confirmado por el Estado. Pero la ausencia de registros civiles en la Patagonia, o el hecho de que los pocos jueces no se movilizaran hacia donde las poblaciones lo requerían, impedían la sustanciación, no solo del matrimonio civil, sino del matrimonio por iglesia que 
resultaba luego de aquel. Fray Guido Depedri en el mismo informe afirma entonces que, no obstante los logros en bautismos y confirmaciones, hubo pocos matrimonios religiosos,

Debido esto a la existencia del Matrimonio Civil; pues el Misionero no puede bendecir ninguna unión sin estar seguro de la celebración del acto Civil; y como los jueces encargados del Registro no salen casi nunca de su oficina, los que viven a larga distancia, no pueden presentarse ante los juzgados, abandonando su casa y sus haciendas; $y$ menos pueden pagar para llamar a su domicilio a los empleados referidos, con el fin de llenar las fórmulas de la ley, y legitimar a sus hijos. Por esto muchos se ven casi obligados a vivir criminalmente sin poder gozar de los beneficios de la ley, y sin que el Sacerdote pueda bendecir su unión, en las excursiones que hace a la campaña (DEPEDRI, 1895, p. 789-790).

En la Memoria de 1896 el obispo Juan ${ }^{21}$ envía al ministro Bermejo un informe en el mismo sentido. En el protesta contra las "uniones ilegitimas" realizadas por no existir unión canónica. Al existir Registro Civil tan lejos y por no visitar el juez dichos poblados no pueden sustanciarse los casamientos bajo el rito católico. No obstante informa que en el Valle del Limay hubo 230 bautismos de los cuales 170 eran hijos de uniones "ilegitimas".

El ejemplo de los matrimonios identifica la existencia de un conflicto que puede ser interpretado en tres niveles que se secundan: el Estado ausente; una iglesia extranjera que no puede anteponerse a ese Estado ausente; y la protesta frente a los límites que encontraba - producto de esta ausencia - la "civilización" de los pobladores nativos. En ese contexto, y desde la perspectiva de los curas que enviaban los informes, solo las obras evangélicas encauzaban a los poblados dispersos por la Patagonia. Así escribía Juan Cagliero, desde otra jurisdicción de la Patagonia, al ministro Antonio Bermejo.

\footnotetext{
${ }^{21}$ Aunque en la fuente seleccionada solo se hace referencia al nombre del obispo, suponemos que se refiere nuevamente a Juan Cagliero. No obstante respetaremos solo el citado del nombre en la sección bibliográfica.
} 
El año transcurrido fue fecundo en obras evangélicas para el bien de los Indígenas bastante numerosos y muy desparramados en estos desiertos, y en obras de adelantos y progreso para el bienestar de las colonias, que se van poblando cada día más y caminando hacia los saludables senderos de la religión, de la moral y de la civilización (CAGLIERO, 1894, p. 791).

Tal como adelantamos, el concepto de "desierto" se comportaba como un eufemismo. No era interpretado en el sentido de "despoblado", sino de "falto de civilización”. Por otro lado al ser muchos de los pueblos indígenas de carácter nómade, era factible no encontrar población asentada en muchos kilómetros a la redonda. Las excursiones misioneras (misiones volantes) recorrían los valles a la vera de los ríos, es por eso que luego de explicar por dónde incursionaban las misioneras, donde se establecieron y las visitas realizadas a los "Indios Tehuelches" Cagliero afirmaba que:

\begin{abstract}
Estas excursiones apostólicas y los trabajos evangélicos en las Residencias y Estaciones de misión, dieron por resultado la conversión de muchos indígenas, el bautismo de millares de criaturas, además de los consuelos religiosos proporcionados a los pobres moradores del desierto, con ventajas inmensas para la instrucción moral y religiosa y para la civilización cristiana de estos nuevos pueblos, que, sin duda alguna, van a ser los primeros cimientos de una futura y floreciente provincia (CAGLIERO, 1894, p. 792).
\end{abstract}

El informe del obispo Cagliero continua subrayando la importancia de la tarea de las misiones y solicitando, nuevamente, los recursos provenientes del gobierno nacional.

En Rawson, Capital de la Gobernación del Chubut, nuestros Padres y nuestras Hermanas son valla a la herejía vecina y salvaguardia para los católicos Argentinos, cuyos hijos frecuentan la Iglesia y los dos colegios de la Misión. Y como se impusiere la necesidad de un hospital en aquella tan apartada comarca, ya se está edificando con los recursos de la población, de la Misión y, esperamos, también del Superior Gobierno (CAGLIERO, 1894, p. 793-794). 


\title{
AUSENCIA DEL ESTADO E INTERVENCIÓN DE LAS MISIONES EN EL PROGRAMA CIVILIZADOR
}

En el marco de la estructuración del Estado, la escolarización se presentaba como un elemento articulador clave para la conformación nacional entre los sectores educables. Una vez conformado el aparato institucional y normativo que dio forma al sistema escolar nacional, la elite dirigente buscó expandirlo a todas las regiones del territorio, sin embargo pasaron muchos años hasta que lograra hacerlo, y nunca en forma definitiva. María de los Milagros Pierini desarrolla en sus trabajos una descripción respecto al abandono que el Estado central hacía de la región hacia fines del siglo XIX.

\begin{abstract}
Frente a estas carencias, que eran sentidas como un abandono por parte del Estado, la población fue implementando diversas medidas: los padres realizaban frecuentes reclamos -ampliamente difundidos por los periódicos- a las autoridades para que se crearan más escuelas, algunos enviaban a sus hijos a estudiar a Punta Arenas o a Europa, los estancieros contrataban docentes o personas idóneas para que impartieran a los niños en sus hogares los conocimientos básicos debiendo luego continuar sus estudios en internados en otras localidades, tanto en Santa Cruz como en Buenos Aires o Europa y, la que es objeto de nuestro análisis, la implementada por la Congregación Salesiana en sus colegios e internados situados en la costa atlántica del Territorio desde los comienzos del siglo XX (PIERINI, 2010, p. 226).
\end{abstract}

Entendemos que estas "carencias", o bien, esta ausencia del Estado en el sur del territorio, fueron, en gran parte, producto del impacto de las crisis económicas de 1873 y luego de la de 1890. El recorte presupuestario y la reorientación del gasto hacia otros ítems del presupuesto público limitaron materialmente las posibilidades de expansión de las instituciones estatales por los territorios patagónicos. La educación buscaba homogenizar, además, un componente central en el marco de la inclusión del Estado argentino al mercado mundial; la estructuración de una mano de obra formada en los requerimientos del modo de producción capitalista. 
Al no desarrollarse experiencias estatales en número suficiente, dicha tarea recayó en manos de experiencias alternativas al Estado, tales como las escuelas de los colonos europeos o (tal como mostramos centralmente en este trabajo) de los misioneros salesianos. Por ser los colonos europeos (tanto los galeses como los italianos), trabajadores, agricultores, artesanos, en los términos comprendidos por el desarrollo capitalista, la tarea civilizatoria se abocó principalmente a los poblados indígenas ya que "eran vistos en una situación de salvajismo e infantilismo" (BAEZA, 2008, p. 28). El gobierno nacional se valió de estas experiencias para permitir la tarea educativa y convertir a aquellas poblaciones nativas (que no habían sido exterminadas) en asequibles para el mercado de trabajo nacional.

La tarea de los salesianos fue aceptada en tanto que los postulados de Don Bosco, fundador de la orden, coincidían con los intereses que la elite gobernante buscaba para aquellas poblaciones. Tal como plantea Nicoletti "Don Bosco insistió sobre las posibilidades de aprendizaje de cada grupo y la necesidad de 'civilizarlos', por medio de la evangelización y la educación para lograr su inserción social en claves de sumisión y moralización católica" (NICOLETTI, 2008, p. 147). Las reducciones buscaban modificar el modo de vida nómade de los pobladores originarios, por un programa civilizador. "Traducido en términos concretos, el plan "civilizatorio" significaba vivir en poblado con casa y familia, cultivar la tierra, criar ganado, respetar la propiedad ajena, administrar los bienes y ser escolarizados" (NICOLETTI, 2008, p. 150).

Además de la imposibilidad, por parte del Estado, de alcanzar a cubrir las necesidades educativas en la Patagonia, producto de las carencias económicas antes mencionadas, es central tener en cuenta que el sistema educativo nacional tampoco había sido planeado para la infancia indígena. La orientación educativa buscaba alfabetizar y nacionalizar a los hijos de los criollos y los inmigrantes europeos, a quienes se pensaba como los destinatarios principales de las labores que el mercado demandaba. Como afirma Sofía Thisted: 
No sólo para la infancia indígena no se imaginó la escuela sino que, al desarraigar a las comunidades y separar a sus integrantes, se procuró interrumpir los procesos formativos que acontecen en el seno de sus grupos familiares. La inclusión a las sociedades modernas para estos niños y niñas no será a través de la escolaridad sino de la temprana inclusión en el trabajo doméstico, frecuentemente separados de sus madres y en condiciones muy similares a las de la esclavitud (THISTED, 2014, p. 141).

Al no haber sido la educación del Estado la que alcanzó a los poblados indígenas, la educación católica fue la que intentó cumplir con dicha tarea. No fue una educación formal en los términos de la pedagogía moderna, se formaba en el trabajo y a través de la catequesis. La evangelización salesiana cumplió, entonces, con la "nacionalización” de algunos de estos poblados indígenas.

El cacique Namuncurá estuvo también en Viedma con el mismo objeto; el Capitanejo Curuhinca, establecido cerca de la Cordillera, recibió con muchos de los suyos el beneficio de la Religión y lleno de satisfacción, después del Bautismo, exclamaba: "Ahora estar contento yo y mi gente; ahora ser hijos de Dios y buenos Argentinos” (JUAN, 1896, p. 495.496).

En este informe, enviado al ministro en 1896, el obispo daba cuenta de uno de los resultados más esperados por parte del Estado nacional. La conversión del cacique y toda su gente implicaba el sometimiento de aquella población. Es difícil distinguir si la conversión fue resultado de un verdadero acto de fe, o bien una táctica de supervivencia establecida por los indígenas. El reconocimiento de la propia derrota se plasmaba así en la aceptación del "Dios" impuesto por los misioneros.

Los indígenas conciliaron, en su integración, la idea de "ser hijos de Dios" con el sometimiento a una autoridad nacional rompiendo con el precepto cristiano de un Dios universal, pero aproximándose a lo esperado por la elite gobernante del país. El planteo de ser ahora "buenos Argentinos", luego de recibido el bautismo, concluyó con los objetivos que el mismo Estado no podía 
alcanzar por sus propios medios.

\section{DOMINACIÓN, INTEGRACIÓN Y ESTADO}

Las crisis económicas de fines del siglo XIX limitaron las posibilidades, por parte del Estado, de avanzar sobre los territorios patagónicos. Luego de las campañas de exterminio el Estado no logró asentar allí sus instituciones. A las carencias económicas se le agregaba la falta de personal preparado (en especial de maestros y sacerdotes formados en el país) así como las complejidades ofrecidas por las particularidades geográficas de la región.

El retraso en la apertura de escuelas y en la proliferación de juzgados provocó un freno en la tarea "nacionalizadora" del Estado sobre la población local. Es tan solo una de las explicaciones del afloramiento de diferentes experiencias educativas.

La experiencia más significativa (y con la que el Estado tuvo que conciliar, producto de la importancia y la similitud de la tarea) fue la de la orden salesiana. La misma cumplió con la tarea de "formar" a los pobladores originarios mediante el trabajo y la evangelización.

Realizamos una descripción sobre cómo eran tratados esos pueblos por los salesianos y sobre la importancia de "cristianizarlos". El Estado "dejo hacer", no solo porque se cumplía con la tarea "civilizatoria" a un costo económico más bajo, sino principalmente por otros motivos. En primer lugar, la evangelización permitía la transformación de costumbres sociales alejadas de la forma de organización capitalista -que era adoptada por el Estado argentino-, por otra más vinculada a los nuevos requerimientos del mercado de trabajo. En segundo lugar, la conversión, el bautismo y el matrimonio, eran entendidos como instituciones que daban paso a la "nacionalización" de poblaciones que, hasta ese momento, no se encontraban bajo la órbita del control estatal.

Se desarrolló así un doble juego de dominación e integración: la 
ausencia parcial del Estado luego de un proceso de intervención violenta y división de tierras ocupadas por los nativos; la intromisión y la mediación de instituciones que no se encontraban bajo su control - como las misiones salesianas - pero que respondían a los intereses (en última instancia) de la política de una elite gobernante que intentaba avanzar sobre ellos en un proceso continuo de dominación, integración y, en algunos casos, exterminio.

\section{REFERENCIAS}

ARRECHE, Francisco. Informe de las misiones salesianas de la Patagonia en Viedma. In: Memoria presentada al Congreso Nacional de 1893 por el Ministro de Justicia, Culto e Instrucción Pública. Buenos Aires, 1893, p. 419.

BAEZA, Brígida. La escuela y la emergencia de 'imprimir' nacionalidad en niños/as de la frontera chileno-argentina de Patagonia Central. El papel de los docentes como productores identitarios. In: OSSANA, Edgardo (dir.).

Docentes y alumnos. Protagonistas, organización y conflictos en las experiencias educativas patagónicas. Historia de la Patagonia Austral. Tomo II. Buenos Aires: Prohistoria, 2008. p. 15-49.

BALESTRA, Juan. Culto. In: Memoria presentada al Congreso Nacional de 1892 por el Ministro de Justicia, Culto e Instrucción Pública. Buenos Aires, 1892, p. LXXXI.

BANDIERI, Susana. Ampliando las fronteras: la ocupación de la Patagonia. In: LOBATO, Mirta (dir.). Nueva historia argentina. El progreso, la modernización y sus límites (1880-1916). Buenos Aires: Sudamericana, 2000. p. 119-177.

BRIONES, Claudia. Cartografías argentinas. Políticas indigenistas y formaciones provinciales de alteridad. Buenos Aires: Antropofagia, 2008.

CAGLIERO, Juan. Anexos de justicia y culto. In: Memoria presentada al Congreso Nacional de 1894 por el Ministro de Justicia, Culto e Instrucción Pública. Buenos Aires, 1894, p. 561-562.

DEPEDRI, Guido. Misiones salesianas en la Patagonia. In: Memoria presentada al Congreso Nacional de 1895 por el Ministro de Justicia, 
Culto e Instrucción Pública. Buenos Aires, 1895, p. 789-790.

DEVOTO, Fernando. Historia de la inmigración en la Argentina. Buenos Aires: Sudamericana, 2003.

DUARTE, Oscar Daniel. Consequences of the 1873 economic crisis for the Argentinian State educational design. Paedagogica Historica, Taylor \& Francis, Londres, v. 52, p. 704-717, 2016.

FIORUCCI, Flavia. Ideas e impresiones de un funcionario viajero: Raúl B. Díaz el primer inspector de Territorios Nacionales (1890-1916). Anuario de la SAHE, Buenos Aires, v. 16, n. 2, p. 82-92, 2015.

JUAN. Misión salesiana de la Patagonia. In: Memoria presentada al Congreso Nacional de 1896 por el Ministro de Justicia, Culto e Instrucción Pública. Buenos Aires, 1896, p. 495-496.

MOLINA, Victor. Plan de estudios para las Escuelas Normales - informe de la inspección de Colegios Nacionales y Escuelas Normales. In: Memoria presentada al Congreso Nacional de 1892 por el Ministro de Justicia, Culto e Instrucción Pública. Buenos Aires, 1886, p. 465.

NICOLETTI, María. 'Derecho a ser educados': conceptos sobre educación y evangelización para los indígenas de la Patagonia a través del escrito inédito de un misionero salesiano. Anuario de la SAHE, CaRol-Go, Buenos Aires, n. 4, p. 137-155, 2002/2003.

NICOLETTI, María. El modelo reduccional salesiano en Tierra del Fuego: educar a los 'infieles'. In: OSSANA, Edgardo (dir.). Docentes y alumnos. Protagonistas, organización y conflictos en las experiencias educativas patagónicas. Historia de la Patagonia Austral. Tomo II. Buenos Aires: Prohistoria, 2008. p. 137-165.

PIERINI, María. Iglesia y Estado en los comienzos de la educación en Santa Cruz: Los salesianos. In: OSSANA, Edgardo (dir.). La educación en la Patagonia Austral: el rol del Estado. Historia de la educación de la Patagonia Austral. Tomo III. Buenos Aires: Prohistoria, 2010. p. 225-252.

PUIGGRÓS, Adriana. Historia de la educación argentina, I. Sujetos, disciplina y currículo en los orígenes del sistema educativo argentino (18851916). Buenos Aires: Galerna, 2006.

PUIGGRÓS, Adriana. Qué pasó en la educación argentina. Breve historia desde la conquista hasta el presente. Buenos Aires: Galerna, 2009. 
RECALDE, Héctor. El primer congreso pedagógico (1882). Buenos Aires: CEAL, 1987.

RUIZ, Juan. Sociedad civil, Estado y educación en Rio Gallegos. Debates y movilización en torno a la educación patagónica. In: OSSANA, Edgardo (dir.). Sujetos, proyectos y conflictos en la constitución del sistema educativo de Santa Cruz. Historia de la Patagonia Austral, Tomo I. Buenos Aires: Prohistoria, 2006. p. 97-124.

SARMIENTO, Domingo. Editorial. El monitor de la educación común, Buenos Aires, n. 1, p. 1, 1881.

SEGATO, Rita. La Nación y sus otros. Buenos Aires: Prometeo, 2007.

THISTED, Sofia. Políticas, retóricas y prácticas educativas en torno a la cuestión de las 'diferencias'. Itinerarios de un siglo largo en el tratamiento de la cuestión de migrantes e indígenas. In: MARTINEZ, Maria; VILLA, Alicia (comp.).

Relaciones escolares y diferencias culturales: la educación en perspectiva intercultural. Buenos Aires: Noveduc, 2014. p. 133-170.

ZORRILLA, Benjamín. Colonias y territorios nacionales. Informe de Educación Común, Tomo I, parte 2, Buenos Aires, 1886.

OSCAR DANIEL DUARTE es Doctor y Profesor de Historia. Facultad de Filosofía y Letras UBA. Docente de historia en la Universidad de Buenos Aires y en la Uade.

E-mail: danielduarte979@gmail.com

(ib) https://orcid.org/0000-0002-2113-605X

Recebido em: 22 de janeiro de 2018

Aprovado em: 30 de abril de 2019

Revista História da Educação - RHE

Associação Sul-Rio-Grandense de Pesquisadores em História da Educação - Asphe

Artigo de acesso aberto distribuído nos termos de licença Creative Commons. 